\title{
A Review Social structure of Gujjar and Bakarwal of Jammu and Kashmir
}

\section{- Manju Dwivedi}

Correspondence to : Manju Dwivedi National College of Education, Purkhoo Camp, Jammu (J\&K) India

Paper History :

Received : 16.11.2017; Accepted : 26.02.2018 reports.
ABSTRACT : Gujjars and Bakarwals in Jammu and Kashmir are socially much backward as compared to other communities of state. They are still following the conventional way of living in wood or mud houses with paddy and forest grass roof besides some houses are now made up of brick and stones. They move with their whole family including children and womenduring winters towards warmer areas of lower Himalayas and comeback towards Bungus valley and other places of cattle grazing areas of Kashmir in summer season. Their movement is based on availability of green fodder for their cattle and also to avoid severe cold and snowfall that affect the health, growth, reproduction, milk production, and lactationetc of their livestock which are major source of livelihood. Their customs mainly different from other ethnic groups and general society in various means like, in their habitats, degree of isolation, customs, beliefs, traditions, etc. But they also interact with other communities at the larger scale. They constitute more than 11.9 per cent of the total population of the state as per 2011 Census. In this paper an efforts has been made to study the social profile of Gujjar and Bakarwal on the basis of secondary sources of literatures i.e. population census of India 2001 and 2011, journals, articles, books and

KeY Words : Gujjar, Bakarwals tribes, Social structure, Dresses, Customs, Livestock

How To Cite This Paper : Dwivedi, Manju (2018). Social structure of Gujjar and Bakarwal of Jammu and Kashmir. Internat. Res. J. Agric. Eco. \& Stat., 9 (1) : 232-238, DOI : 10.15740/HAS/IRJAES/9.1/232-238. 